\title{
THE CENTRAL NERVOUS SYSTEM IN PURPURA HEMORRHAGICA ${ }^{1}$
}

By Alfred Gordon, M.D.

of PHILADELPHIA

In purpura hemorrhagica the chief characteristic symptom is the bleeding from the mucous membranes, although the skin may also be the seat of bleeding. In some cases, however, the cutaneous hemorrhages are more extensive than those of the mucous membranes, so that the skin looks as if spattered with a paint-brush, and large ecchymoses may cover the limbs and the trunk. There are therefore two forms of purpura hemorrhagica: one with and the other without skin symptoms. In both forms, all authors agree, epistaxis is the most frequent occurrence of the disease (50 per cent.). The gums are the next frequent seat of hemorrhage (20 per cent.).

Hemorrhage may occur from other places-intestines, stomach, uterus, urinary apparatus and rarely from the lungs. Hemorrhage in the brain has not been reported in cases of purpura hemorrhagica.

A few cases of cerebral hemorrhage have been observed in hemophilia. In the latter affection hemorrhage may take place after the least trauma from the slin, mucous membranes, in inner organs including the brain. Spontaneous cerebral hemorrhage may occur in hemophilia, as the cases of Hauck ${ }^{2}$ testify. Here layers of blood were observed on the surface of the dura, beneath the dura and in the ventricles, but the brain substance itself, apart from being white, was found to be normal.

The involvement of the nervous system in general has been observed by a few writers. Armand-Delille ${ }^{3}$ reports a segmental distribution of the purpuric outbreak similar to that in herpes zoster. Pressure from a surgical dressing producing a purpuric eruption over an area supplied by certain cutaneous nerves was observed by Gougerot et Salin. ${ }^{4}$ The symmetrical distribution of the eruption seen in purpura is regarded as an indication of some relation between the nervous system and purpuric outbreak. Lumbar punc-

1 Read and specimens presented at the meeting of the Philadelphia Neurological Society, March 28, I919.

2 Münch. mediz. Wochenschr., I9I3, p. II47.

${ }^{3}$ Rev. Neurol, I905, XIII, p. 775.

+ Arch. des maladies du cœur, Igi i, LV, p. 86. 
ture has sometimes shown a meningeal reaction, viz., lymphocytosis and considerable albumen.

No record appears to be in existence as to the intimate histological state of the nervous tissue in cases of purpura hemorrhagica. In the anatomic-clinical case described below no hemorrhage was found on the surface of the brain or in the cerebral cavities as in the hemophylic cases, but, on the contrary, profound changes were seen in the tissue of the brain and spinal cord and everywhere confined exclusively to the gray matter. If in anemic conditions the lesion is confined to the white matter. viz.. nerve fibers, here in purJurat hemorthagica the lesion affects exclusively the cells of the gray matter throughout the entire central nervons system. The lesion consisted of destruction of cells and formation of racuoles. The case is at follows:

Child (). M., make, five years of age suldenly commenes hleeding frem the gams and mucous membratie of the mouth. The chitd was

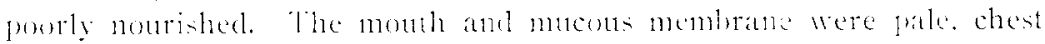
and lungs were normal. The heart somnds were weak. Vhomen normal. Extremities momal. The kne-jerk were matkedly diminsohed

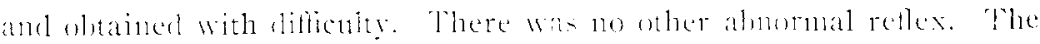
temperature was submormal (o) per cent.).

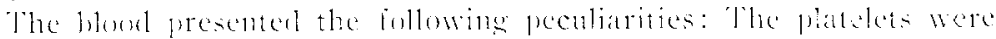

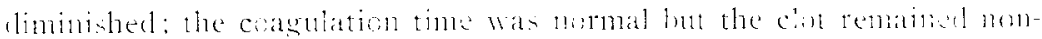
combatile, all circmostances listinguishing the conditon from hemophilizi. The litte patient was treated with transfusion of human blood, but without effect. A subcutaneous injection of thrombo-plastin also remained ineffectual. The patient soon died. Autopsy was performed I 2 hours later: The abdominal and thoracic viscera were found normal. The central nervous system presented macro- and microscopically the following interesting features:

The brain and spinal cord on gross appearance were extremely pale. This pallor was eviclent also at the base of the brain and on cross sections. The tissue was very soft and appeared flattened as if in a state of collapse. Nowhere cotll be seen a single vessel showing the presence of blood in it. The circle of Willis merely presented a series of white bands which were flattened because of absence of blood in the vessels. Large sections of the brain revealed the same unusual pallor over entire sectioned surfaces. Histological examination presented the following condition:

Brain.-Sections of the cerebral cortex shows diffuse vacuolation. A very large number of cells are destroyed. Empty round spaces filled or not with blood clots or with round cells are seen over extensive areas. In some places empty spaces of the shape of blood vessels on one side 
of which a row of round cells is seen. The majority of the spaces are round, but of unequal size.

Identical condition was found over the entire cortex but much more pronounced in the motor area than in any other portion. The occipital lobe was the least affected. No vacuolation was observed in the layers of the cerebellar cortex.

Sections of the brain substance showed a similar condition in the basal ganglia. Vacuolation with destruction of cells, round spaces with clots of blood occupying only the cerebral portion of the latter are seen

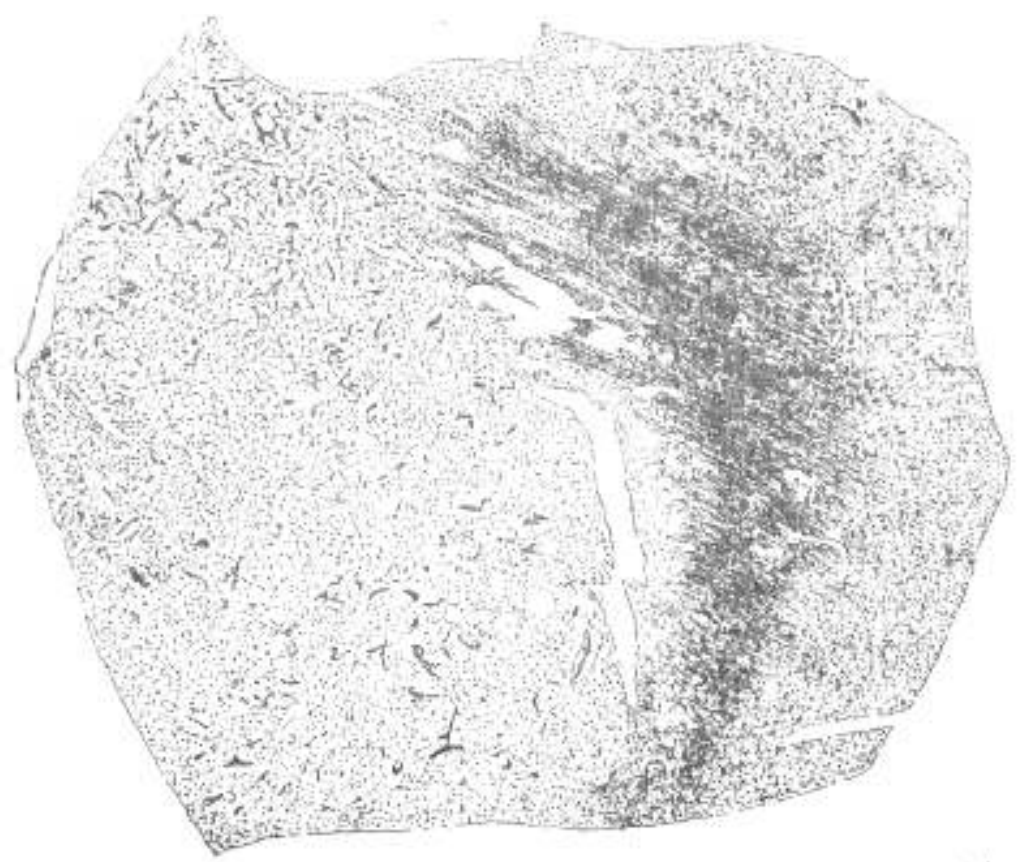

Section of the motor cortex showing destruction of the cells and vacuolation.

exclusively in the gray matter, irregularly distributed more in one hemisphere than in the other. The condition was totally absent in the white substance of the brain. No vacuolation, no empty spaces with or without clots of blood or cells could be traced within or along any of the tracts.

The midbrain and medulla presented an identical picture. Wherever there was gray matter, viz., in various nuclei, the above-mentioned empty spaces with or without blood clots were observed. The crura, the tracts in the pons, the pyramids were totally intact.

In the spinal cord the fathological state was precisely the same. The posterior cornua are very much less involved than the anterior ones, and 
one side more than the other. On some sections the entire cornua appeared as an empty space with very rare cells here and there. On other sections some cells were preserved and the vacuolation was less pronounced. All degrees of destruction of gray matter were seen. The cervical portion was more affected than the thoracic and lumbar.

To sum up, throughout the entire central nervous system, with the exception of the cerebellum, the pathological process was confined exclusively to the gray matter whether it was the cortex or

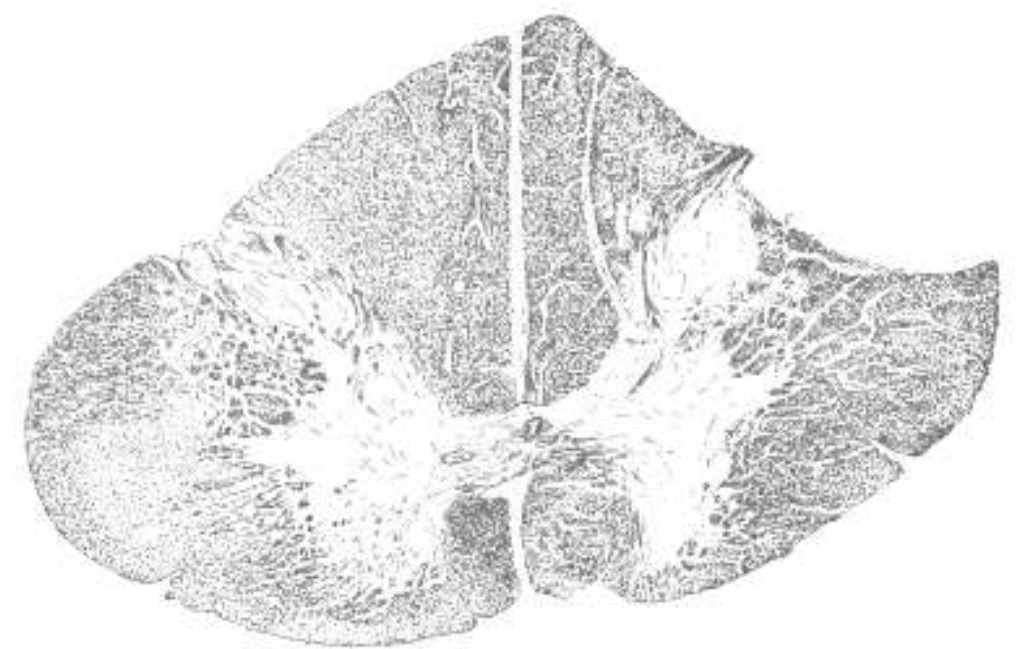

Section of spinal cord showing destruction of the cells of the gray matter and extensive vacuolation.

within the cerebrum, medulla and spinal cord. The lesion consisted chiefly of vacuoles situated between the cells, thus destroying the cells in the vicinity. Some blood vessels are also found empty or else filled with clots of blood.

Multiple hemorrhages evidently took place simultaneously in many segments of the nervous axis. The vacuolated spaces indicate complete absorption and disappearance of the cells destroyed by the hemorrhages.

In analyzing the origin of the disorder a question naturally arises: why such an extensive destruction of gray matter throughout the entire central nervous system? A reply to this query may be found in the distribution of the blood vessels. First of all, the blood supply of the gray substance is very abundant and considerably more so than in the white matter. In the next place, the central branches are of a terminal variety, that is, their capillaries do not anastomose with those of other branches. 
The latter circumstance particularly is apt to explain not only the extent of the destruction, but also its rapidity and the absence of tendency for repair: the tissue being supplied by a terminal vessel, which does not possess anastomotic branches, is bound to succumb beyond repair when that vessel is ruptured.

While this anatomical fact may give some explanation of the intensity of the lesion, it neverthless fails to present an adequate understanding of another problem, namely, that of its confinement to the gray matter exclusively. Finally, why is it that in severe anemias the white substance is invariably involved, and the gray tissue remains intact or rarely impinged upon? Why this difference should exist is problematical.

Perhaps improvement in laboratory technique with regard to the vascular supply of gray and white substance will enable us to solve these interesting problems. 